\title{
A Phase Shifted Full Bridge Converter Design for Electrical Vehicle Battery Charge Applications Based on Wide Output Voltage Range
}

\author{
Sevilay Cetin \\ Pamukkale University \\ Technology Faculty, Denizli, Turkey \\ scetin@pau.edu.tr
}

\author{
Alparslan Astepe \\ Beyobası Energy Generation Co. Inc. \\ Bozdogan, Aydın, Turkey \\ aastepe@akfen.com.tr
}

\begin{abstract}
In this study, high efficiency design procedure of a phase shifted full bridge (PSFB) converter is presented for on-board electrical vehicle (EV) battery charger. Presented design methodology used lithium-ion battery cells because of their high voltage and current rates compared to a lead-acid battery cells. In this case, PSFB converter can be regulated wide range output voltage with while its soft switching operation is maintained. The basic operation principles of PSFB converter is defined and its soft switching operation requirements are given. To evaluate the performance of the converter over wide output voltage range, zero voltage switching (ZVS) operation of converter is discussed based on dead time requirement. To improve efficiency, the snubber inductance effects on soft switching over wide output voltage range are evaluated. Finally, operation of the PSFB converter is validated experimentally with a prototype which has 42-54 V/15 A output range at $200 \mathrm{kHz}$ switching frequency.
\end{abstract}

Keywords- Phase shifted full bridge converter, EV battery chargers, high efficiency, wide range output voltage regulation.

\section{INTRODUCTION}

The use of electrical vehicle (EV) and plug in hybrid EV increases every day due to their advantages in economic area and global warming. The battery charger of EV can be designed on board or off-board. On-board systems provides the flexibility to end user to charge vehicle's battery from any possible power outlet [1]. However, the battery charger brings extra weight, volume and cost to EV as discussed in [2]. The proposed studies in [3] and [4] evaluates the high power density on-board battery chargers. The study in [3] gives the design methodology to reach high efficiency and decreased volume. In [4], integrated onboard chargers are discussed. Integrated chargers use motor windings as filter inductors or transformer and motor inverter is used as bidirectional AC-DC converter so their control and design results in complex solution to implementation.

In order to compete EV with internal combustion engine vehicle, on-board battery charger should be design with high power density, high efficiency and simple structure as discussed in [5] and [6]. Recently, in order to keep power density high, lithium-ion battery cells are usually used because they have higher voltage and current rate compared to the other battery cell and this provides high power density battery package [7], [8]. In this case, lithium-ion battery chargers can regulate wide output voltage range.

A battery charger usually uses a front-end power factor correction boost converter at the first stage and a $\mathrm{dc}-\mathrm{dc}$ converter regulates the output voltage at the second stage as designed battery chargers in [9] and [10]. For high power density and high efficiency applications, the soft switching dc-dc converters are usually preferred [2]. The phase shifted full bridge (PSFB) pulse width modulated (PWM) converter [1] and resonant converters [9]-[11] work naturally with soft switching, they don't require additional circuit components. Therefore, they are preferred for the second stage of EV battery chargers. The resonant converter can regulate the output voltage with the change of switching frequency. The frequency change is not desired application in power converter design because the magnetic component optimization is difficult at the changing frequency range. Besides, sinusoidal change of current and voltage values require semiconductors with high rates [12]. PSFB PWM converter works with soft switching by the applying phase delay to control signals of conducted diagonal primary switches. There are a lot of design procedure of PSFB converter for constant output voltage application is presented in the literature [13][18]. Among them, [13], [14] and [17] are focused on high efficiency design procedure for data center or telecom applications. The studies, given in [15] and [18], evaluate the light load efficiency improvement with dead time and delay time optimization in server power systems. In [16], an auxiliary circuit is included in PSFB converter to extend soft switching operation range of primary switches for welding machines. The performance of PSFB converter for wide range output voltage regulation, required in li-ion battery chargers, is very different compared to constant output voltage applications mentioned above.

Recently, an on-board battery charger design procedure using PSFB converter is presented in [1] and [19]. In the proposed methods, performance of battery charger is evaluated by the use of $\mathrm{SiC}$ power semiconductors. The volume, weight and efficiency of the battery charger is optimized for on-board system. However, the performance and design procedure of 
PSFB converter based on wide range output voltage regulation is not discussed in detail.

In this study, a PSFB PWM converter design consideration based on wide output voltage range for the second stage of an on-board battery charger is discussed. The output voltage range is determined with the series connection of enough lithium-ion battery cell. According to lithium-ion battery charge characteristic, soft switching and efficiency performance of PSFB converter over wide output voltage range is evaluated. The optimum operation point to maintain soft switching operation of the converter for wide output voltage range is determined. To validate theoretical evaluations, a prototype operating at $200 \mathrm{kHz}$ and regulating output voltage between $42 \mathrm{~V}$ and $54 \mathrm{~V}$, is built in laboratory. The soft switching operation and the output regulation of the converter is tested for wide output voltage range.

\section{BASIC PRINCIPLES OF PSFB CONVERTER}

The circuit scheme of PSFB PWM converter is shown in Fig. 1. $S_{1}-S_{4}$ are the primary MOSFETs, DR1 and $\mathrm{D}_{\mathrm{R} 2}$ are rectifier diodes, $L_{m}$ is the magnetizing inductance, and $L_{s}$ is the snubber inductance which includes leakage inductance of the transformer and extra added inductance. $L_{o}$ is the output filter inductor and $C_{o}$ is the output filter capacitor. $V_{i n}$ is the input voltage source, $V_{o}$ is the battery voltage, $\mathrm{N}$ is the turns ratio of the transformer. The theoretical key waveforms of the converter are also given in Fig. 2.

In the powering stages, $\mathrm{S}_{1}-\mathrm{S}_{2}$ or $\mathrm{S}_{3}-\mathrm{S}_{4}$ are turned on and that two MOSFET pairs share one switching period. During the conduction of $\mathrm{S}_{1}$ and $\mathrm{S}_{2}$, at $\mathrm{t}=\mathrm{t}_{0}$, the input voltage is applied to the primary side of the transformer, and the primary current increases linearly. At the secondary side, $\mathrm{DR}_{2}$ is on and the power is transferred to the output. The primary current change can be written as follows:

$$
\frac{d i_{p}}{d t}=\frac{V_{i n}-V_{o}^{\prime}}{\left(L_{o}^{\prime}+L_{s}\right)},
$$

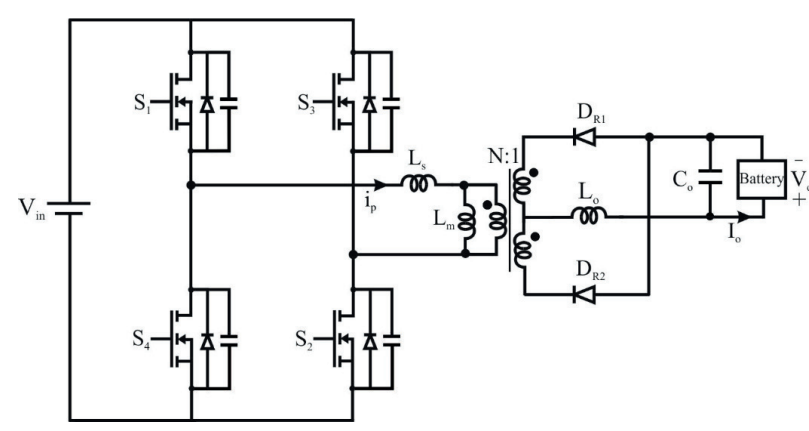

Figure 1. The circuit schematic of PSFB converter.

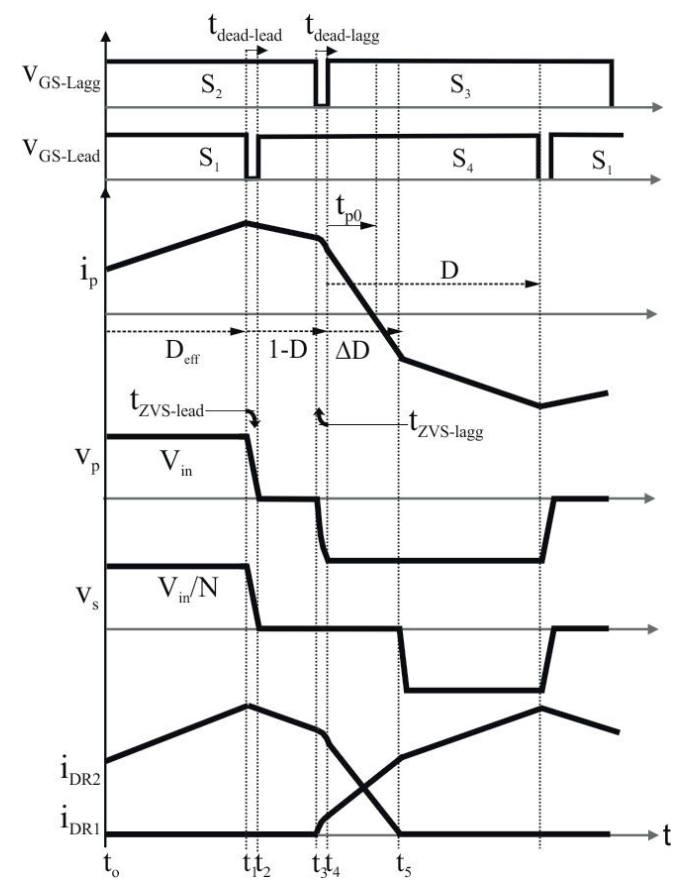

Figure 2. The theoretical key waveforms of PSFB PWM converter.

where $V_{o}$ ' and $L_{o}$ ' represent the reflected output voltage and the output filter inductor to the primary side. Then, at $\mathrm{t}=\mathrm{t}_{1}, S_{1}$ is turned off, and the parasitic capacitors of $\mathrm{S}_{1}$ and $\mathrm{S}_{4}$ MOSFETs are charged and discharged by the reflected output current. At $\mathrm{t}=\mathrm{t}_{2}$, the antiparallel diode of $\mathrm{S}_{4}$ MOSFET turns on when the voltage of the parasitic capacitor of $\mathrm{S}_{4}$ reaches zero. Thus, freewheeling mode starts and the primary windings of the transformer are short circuited. $\mathrm{DR}_{2}$ is still on and conducts the output current. To achieve ZVS turn on for $\mathrm{S}_{4}$ MOSFET, control signal to be turned on $\mathrm{S}_{4}$ should be applied during in the freewheeling mode. The primary current change for freewheeling mode can be written as

$$
\frac{d i_{p}}{d t}=\frac{V_{o}^{\prime}}{L_{o}^{\prime}+L_{s}} .
$$

Then, at $\mathrm{t}=\mathrm{t}_{3}, \mathrm{~S}_{2}$ is turned-off and so the parasitic capacitors of $\mathrm{S}_{2}$ and $\mathrm{S}_{3}$ MOSFETs are charged and discharged. At the secondary side, the output current commutation starts between $\mathrm{DR}_{1}$ and $\mathrm{DR}_{2}$ by the conduction of $\mathrm{DR}_{1}$. Thus, secondary windings of the transformer is short circuited and so the output current cannot be reflected to the primary side. Therefore, $\mathrm{L}_{\mathrm{s}}$ inductance should provide required energy to discharge and charge the parasitic capacitors of the lagging leg switches since there is no current reflected from the output. If the parasitic capacitor of $\mathrm{S}_{3}$ discharges completely, its antiparallel diode turns-on and ZVS turn-on of $\mathrm{S}_{3}$ is achieved at $\mathrm{t}=\mathrm{t}_{4}$. Then, the negative input voltage is applied to the primary side of the transformer. At the secondary side, the output current commutation continues and the secondary windings of the transformer are still short circuited. If the charge and the discharge time interval of parasitic capacitors are neglected, the primary current change 
for the output current commutation can be written as follows:

$$
\frac{d i_{p}}{d t}=-\frac{V_{i n}}{L_{s}} .
$$

The output current commutation interval causes lost duty cycle, $\Delta D$, since no energy is transferred from the input to the output. This situation can be defined approximately as

$$
\Delta D \approx \frac{2 I_{o} L_{s} f_{s}}{N V_{\text {in }}} .
$$

Where $f_{s}$ is the switching frequency, and $I_{o}$ represents the output current. Thus, as shown in Fig. 2, effective duty ratio $D_{\text {eff }}$ can be defined as

$$
D_{e f f}=D-\Delta D \text {. }
$$

Where $D$ is the total duty time applying the switches. The half switching period is completed when the output current commutation is completed at $\mathrm{t}=\mathrm{t}_{5}$. The remaining half cycle works with the same principle but inverse direction of the primary current and voltage.

\section{A. ZVS Requirements of Leading Leg MOSFETs:}

The soft switching operation of leading leg MOSFETs $\left(\mathrm{S}_{1}\right.$ and $\left.\mathrm{S}_{4}\right)$ can be achieved easily with the reflection of output current to the primary side and optimized dead time. The dead time requirement for leading leg MOSFET can be defined as

$$
t_{\text {dead-lead }} \geq t_{d(\text { off })}+t_{r v} .
$$

Where $t_{d(\text { off })}$ represents the turn-off delay time and $t_{r v}$ defines the voltage rising time obtained from datasheet of primary MOSFETs. The duration of charge/discharge of parasitic capacitors defines the ZVS interval and it can be extracted as follows:

$$
t_{Z V S-\text { lead }}=\frac{\left(C_{S 1}+C_{S 4}\right) V_{i n}}{I_{p-t 1}} .
$$

The dead time should be enough to allow charge and discharge of the parasitic capacitors so dead time for leading lead MOSFETs is also defined as

$$
t_{\text {ZVS-lead }} \leq t_{\text {dead-lead }} .
$$

\section{B. ZVS Requirements of Lagging Leg MOSFETs:}

The soft switching operation of lagging leg MOSFETs depends on load condition and it can get poor at light load conditions. Because short circuit condition of secondary windings removes the reflection of the output current to the primary side and so stored energy in $\mathrm{L}_{\mathrm{s}}$ should provide discharge and charge the parasitic capacitors of the lagging leg switches. This condition can be defined as

$$
\frac{1}{2} L_{s} I_{p-c r}^{2} \geq \frac{1}{2}\left(C_{S 2}+C_{S 3}\right) V_{i n}^{2}
$$

Where, $I_{p-c r}$ defines the required minimum primary current to be charged and discharged the parasitic capacitors of lagging leg MOSFETs and $\left(C_{S 2}+C_{S 3}\right)$ represents the equivalent parasitic capacitors during the resonance occurred between $L_{s}$ and parasitic capacitors.

The dead time requirement of lagging leg MOSFETs is different compared to leading leg MOSFETs. The dead time should be enough to charge and discharge of parasitic capacitors as follows:

$$
t_{\text {dead-lagging }} \geq t_{d(\text { off })}+t_{r v} \text {. }
$$

In addition, the dead time also should be ended before primary current falls to zero to prevent reverse resonance and recharge the parasitic capacitors [16], [17]. This can be defined as

$$
t_{\text {ZVS-lagg }} \leq t_{\text {dead-lagg }} \leq t_{p 0}
$$

Where $t_{Z V S \text {-lagg }}$ is the charge and discharge time of the parasitic capacitors of the lagging leg MOSFETs. The duration of the charge and the discharge of the parasitic capacitors defines the ZVS interval and it can be extracted from the equivalent series resonant circuit as follows:

$$
t_{\text {ZVS-lagg }}=\sqrt{L_{s}\left(C_{S 2}+C_{S 3}\right)} \operatorname{tg}^{-1} \frac{V_{\text {in }}}{I_{p-t 3}} \sqrt{\frac{C_{S 2}+C_{S 3}}{L_{s}}} .
$$

Where $t_{p 0}$ is the time duration which the primary current falls to zero in as shown in Fig. 2 and it can be written as

$$
t_{p 0}=\sqrt{L_{s}\left(C_{S 2}+C_{S 3}\right)} t g^{-1} \frac{V_{i n}}{I_{p-t 3}} \sqrt{\frac{C_{S 2}+C_{S 3}}{L_{s}}}+L_{S} \frac{I_{p-t 4}}{V_{i n}} .
$$

\section{PERFormance ANALysis of PSFB PWM CONVERTER BASED ON WIDE RANGE OUTPUT VOLTAGE REGULATION}

In this section efficiency optimization of PSFB converter based on wide range output voltage regulation is discussed. For the output of converter, 14 battery cells connected as series are assumed. According to lithium-ion battery charge characteristic given in Fig. 3 [11], the voltage of a battery cell changes between $3.1 \mathrm{~V}$ and $3.85 \mathrm{~V}$. To evaluate the performance of PSFB converter, several points are addressed on the charge characteristic of li- ion battery 


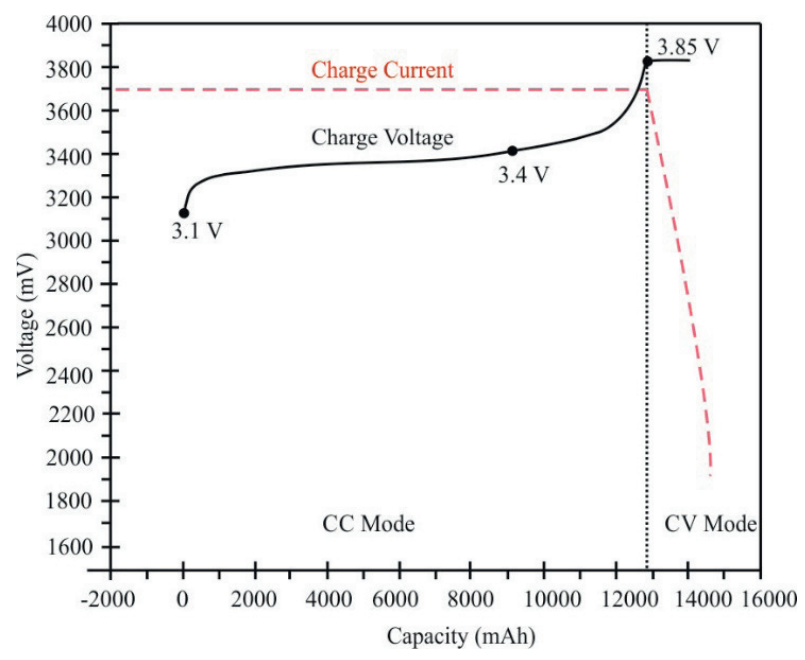

Figure 3. Lithium-ion battery charge characteristic.

cell, given in Figure 3. Four operation points of the battery cell are $3.1 \mathrm{~V} / 15 \mathrm{~A}, 3.4 \mathrm{~V} / 15 \mathrm{~A}, 3.85 \mathrm{~V} / 15 \mathrm{~A}$ and $3.85 \mathrm{~V} / 3 \mathrm{~A}$. Thus, according to assumption of series connection of 14 battery cell, the output voltage range of PSFB converter is changed from $43.4 \mathrm{~V}$ to $53.9 \mathrm{~V}$.

According to soft switching operation conditions of PSFB converter discussed earlier, ZVS turn-on operation of the primary MOSFETs are evaluated for determined output voltage range of battery package. The evaluation should be took into consideration the dead time requirements because duty ratio and so dead time also varies to regulate the output voltage range. The soft switching operation of leading leg MOSFETs is not affected by varying dead time. The varying dead time affects the soft switching operation of the lagging leg MOSFETs. Thus, the dead time optimization of lagging leg over wide output voltage range is discussed in this work. Therefore, the dead time requirement condition for the lagging leg switches is firstly defined.

For the performance analysis, SiC CMF20120D is used as primary MOSFET. According to the rising and falling time obtained from the MOSFET's datasheet, dead time of the lagging leg MOSFETs is calculated as $78 \mathrm{~ns}$ based on equation (10). The ZVS time interval is calculated as $77 \mathrm{~ns}$ based on (12). The time interval, which primary current falls to zero, is obtained as 137 by the use of (13). Thus, following condition should be provided to achieve ZVS turn-on of lagging leg switches.

$$
77 n s<t_{\text {dead-lagg }}<137 n s
$$

In the calculation results given above, $L_{s}$ inductance is selected as $10 \mu \mathrm{H}$ and the equivalent parasitic capacitor of lagging leg MOSFETs, $C_{\text {lagg, }}$, is obtained as 2x120 pF from MOSFET's datasheet. According to dead time requirements, the evaluation results are obtained for constant current operation as given in Table I. The lagging leg MOSFETs of the converter turns-on with ZVS just at $54 \mathrm{~V}$ and they turn-on hardly at the other voltage points since effective duty ratio becomes smaller and dead time is larger. This results in reverse resonance which charges the parasitic capacitor of MOSFETs to the input voltage.

To extend the soft switching operation for wide range output voltage regulation, the value of the snubber inductance, $\mathrm{L}_{\mathrm{s}}$, can be increased but this also increases the lost duty ratio power losses, namely conduction loss occurred during the output current commutation of PSFB converter. In order to see effects of $L_{s}$ snubber inductance on soft switching operation of lagging leg MOSFETs and the conduction loss, a calculation study is performed in Matlab. The dead time change as function of $L_{s}$ and based on full load condition is given in Fig. 4. The maximum extension of time interval, $t_{p 0}$, is limited by $24 \mu \mathrm{H}$ to provide output voltage regulation while the turns ratio of transformer is 6 . If the turns ratio is reduced, the further extension of $t_{p 0}$ is possible but this also results in the increased conduction loss. Therefore, the evaluation procedure is continued with 6 turns ratio. The primary current falls to zero in 263 ns if $L_{s}$ inductance is selected as $24 \mu \mathrm{H}$ as shown in Figure 4. However, at this point, the calculated $t_{Z V S}$ value not provides the required condition for ZVS turn-on of the lagging leg MOSFET because $t_{Z V S}$ should be smaller than dead time, over wide load range, given in Table 1. If $L_{s}$ is selected $20 \mu \mathrm{H}$, the required conditions for $t_{Z V S}$ and $t_{p 0}$ are provided. This operation point provides soft switching operation from $50 \mathrm{~V}$ to $54 \mathrm{~V}$.

TABLE I. SWITCHING OPERATION OF THE LAGGING LEG MOSFETS BASED ON WIDE RANGE OUTPUT VOLTAGE.

\begin{tabular}{|c|c|c|c|}
\hline \multicolumn{4}{|c|}{$\boldsymbol{I}_{\boldsymbol{o}}=\mathbf{1 5} \mathrm{A}, \boldsymbol{V}_{\text {in }}=\mathbf{3 8 5} \mathrm{V}, \boldsymbol{L}_{\boldsymbol{s}}=\mathbf{1 0} \boldsymbol{\mu H}, \boldsymbol{C}_{\text {lagg }}=\mathbf{2 4 0} \mathbf{p F}, \mathbf{n}=\mathbf{6}$} \\
\hline Vo & $\boldsymbol{t}_{\text {dead-lagg }}$ & $\boldsymbol{D}_{\text {eff }}$ & $\begin{array}{c}\text { Turn-on } \\
\boldsymbol{S} \boldsymbol{w} .\end{array}$ \\
\hline 42 & $362.5 \mathrm{~ns}>\mathrm{tp} 0$ & 0.71 & Hard \\
\hline 44 & $325 \mathrm{~ns}>\operatorname{tp} 0$ & 0.74 & Hard \\
\hline 46 & $275 \mathrm{~ns}>\operatorname{tp} 0$ & 0.78 & Hard \\
\hline 48 & $237.5 \mathrm{~ns}>\operatorname{tp} 0$ & 0.81 & Hard \\
\hline 50 & $200 \mathrm{~ns}>\operatorname{tp} 0$ & 0.84 & Hard \\
\hline 52 & $150 \mathrm{~ns}>\operatorname{tp} 0$ & 0.88 & Hard \\
\hline 54 & $112.5 \mathrm{~ns}<\mathrm{t}_{\mathrm{p} 0}$ & 0.91 & ZVS \\
\hline
\end{tabular}

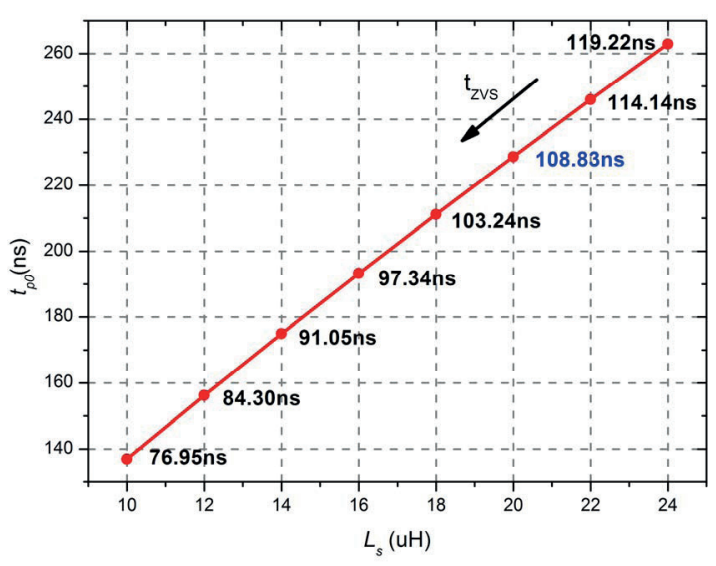

Figure 4. The change of $t_{p 0}$ based on the variation of $L_{s}$. 


\section{EXPERIMENTAL RESULTS}

The presented design procedure of PSFB converter for on-board EV battery chargers is validated by a prototype. The nominal $385 \mathrm{~V}$ dc input voltage is applied to the primary side of the converter. The converter is operated for $42-54 \mathrm{~V} / 15 \mathrm{~A}$ output at 200 $\mathrm{kHz}$ switching frequency. The power semiconductors and the magnetic components used in the prototype are given in Table II. In the performance evaluation of the converter, ZVS turn-on of lagging leg MOSFETs were evaluated.

Fig. 5 provides the drain-source voltage of $\mathrm{S}_{2}$ MOSFET and the primary current with $54 \mathrm{~V} / 15 \mathrm{~A}$ output. For the maximum output voltage of the battery package, ZVS turn-on of the lagging leg MOSFET, $\mathrm{S}_{2}$, is validated with the measured results.

The soft switching operation of $\mathrm{S}_{2}$ MOSFET is also measured for $50 \mathrm{~V}$ output voltage at full load condition and the measured waveforms are given in Fig. 6. Measured results shows that ZVS turn-on of lagging leg MOSFETs is maintained at $50 \mathrm{~V}$.

Fig. 7 provides the measured results while the output voltage is $48 \mathrm{~V}$ with full load condition. As anticipated, soft switching operation of lagging leg switches are lost.

TABLE II. THE USED COMPONENTS IN THE PROTOTYPE.

\begin{tabular}{|c|c|}
\hline Parameters & Values \\
\hline $\mathrm{S}_{1}-\mathrm{S}_{4}$ & $\mathrm{SiC} \mathrm{C} 2 \mathrm{M} 0080120$ \\
\hline $\mathrm{D}_{\mathrm{R} 1}-\mathrm{D}_{\mathrm{R} 4}$ & $\mathrm{DSS} 2 \times 101-015 \mathrm{~A}$ \\
\hline $\mathrm{TR}$ & $\mathrm{E} / 65 / 32 / 27, \mathrm{~N}_{\mathrm{p}}=12, \mathrm{~N}_{\mathrm{s}}=2$ \\
\hline$L_{r}$ & $20 \mu \mathrm{H}$ home made \\
\hline$L_{o}$ & $1.1 \mu \mathrm{H}$ home made \\
\hline$C_{o}$ & $12 \times 22 \mu \mathrm{F}$ ceramic capacitor \\
\hline
\end{tabular}

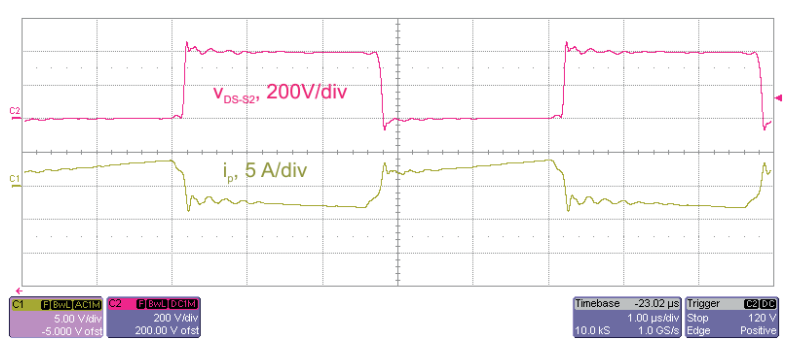

Figure 5. The drain-source voltage of $\mathrm{S}_{2}$ MOSFET ( $\mathrm{v}_{\mathrm{DS}-\mathrm{S} 2}$ ), the primary current (ip) at $V_{o}=54 \mathrm{~V}, I_{o}=15 \mathrm{~A}, f_{s}=200 \mathrm{kHz}$ and $V_{i n}=385$ $\mathrm{V}$.

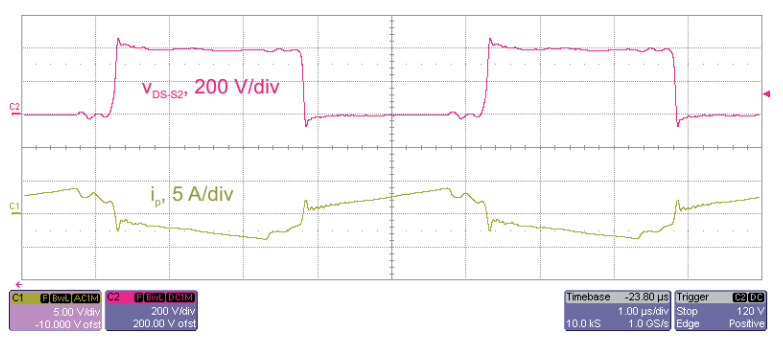

Figure 6. The drain-source voltage of $\mathrm{S}_{2} \operatorname{MOSFET}\left(v_{D S-S 2}\right)$, the primary current at $V_{o}=50 \mathrm{~V}, I_{o}=15 \mathrm{~A}, f_{s}=200 \mathrm{kHz}$ and $V_{i n}=385 \mathrm{~V}$.

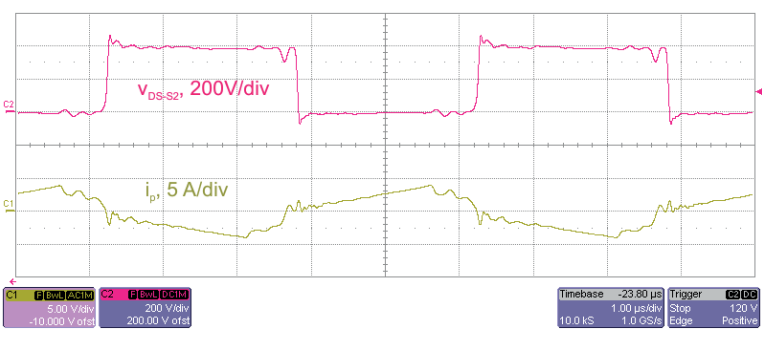

Figure 7. The drain-source voltage of $\mathrm{S}_{2} \operatorname{MOSFET}\left(\mathrm{v}_{\mathrm{DS}-\mathrm{S} 2}\right)$, the primary current at $V_{o}=48 \mathrm{~V}, I_{o}=15 \mathrm{~A}, f_{s}=200 \mathrm{kHz}$ and $V_{i n}=385 \mathrm{~V}$.

Fig. 8 gives the measured efficiency results based on battery voltage with 15 A constant current. The measured maximum efficiency was obtained as $94.4 \%$ with $54 \mathrm{~V} / 15$ A output. The efficiency decreases while the battery voltage decreases because ZVS turn-on operation is not maintained under $50 \mathrm{~V}$ and also output power is decreased.

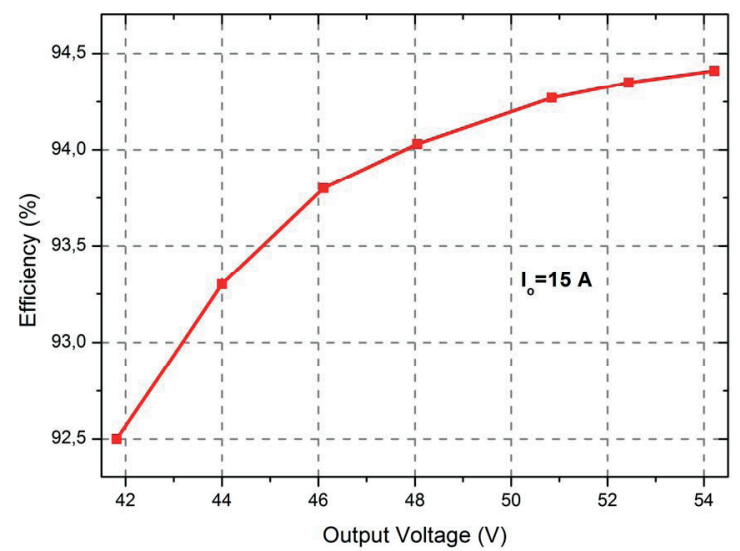

Figure 8. The measured efficiency values as function of battery voltage.

\section{CONCLUSIONS}

In this study, the soft switching operation of PSFB converter is discussed based on wide range output voltage of EV battery chargers. The soft switching requirements of the lagging leg MOSFETs are taken into consideration to evaluate effects of the duty ratio varying to regulate $42-54 \mathrm{~V}$ output voltage range. The snubber inductance value is optimized to $20 \mu \mathrm{H}$ to reach high efficiency over wide output voltage range. The obtained theoretical results are validated with a prototype built with $42-54 \mathrm{~V} / 15 \mathrm{~A}$ at $200 \mathrm{kHz}$. The efficiency variation based on battery voltage range with constant output current was also extracted. The maximum efficiency is measured as $94.4 \%$ with $54 \mathrm{~V} /$ 15 A output.

\section{ACKNOWLEDGMENT}

This work is supported by Pamukkale University Scientific Research Projects Coordination Unit under grant number 2015 FBE057.

\section{REFERENCES}

[1] B. Whitaker, A. Barkley, Z. Cole, B. Passmore, D. Martin, T.R. McNutt, A.B. Lostetter, J.S. Lee, K. Shiozaki, “A highdensity, high-efficiency, isolated on-board vehicle battery 
charger utilizing silicon carbide power devices," IEEE Transactions on Power Electronics, vol. 29, pp. 2606-2617, January 2014

[2] M. Yilmaz, P.T. Krein, "Review of battery charger topologies, charging power levels, and infrastructure for plugin electric and hybrid vehicles," IEEE Transactions on Power Electronics, vol. 28, pp. 2151-2169, May 2013.

[3] M. Grenier, M.H. Aghdam, T. Thiringer, "Design of on-board charger for plug-in hybrid electric vehicle," In Proc. Power Electronics, Machine and Drives, Brighton, England, 19-21 April 2010.

[4] S. Haghbin, K. Khan, S. Lundmark, M. Alakula, O. Carlson, M. Leksell, O. Wallmark, "Integrated chargers for EV's and PHEV's: examples and new solutions," In Proc. Int. Conf. Electrical Machines, Rome, Italy, 6-8 September 2010.

[5] A. Emadi, Y.J. Lee, K. Rajashekara, "Power electronics and motor drives in electric, hybrid electric, and plug-in hybrid electric vehicles," IEEE Trans. Ind. Appl., vol. 55, pp. 22372245, June 2008.

[6] A. Emadi, S.S. Williamson, A. Khaligh, "Power electronics intensive solutions for advanced electric, hybrid electric, and fuel cell vehicular power systems," IEEE Trans. Power Electron., vol. 21, pp. 567-577, May 2006.

[7] M. Chen, G.A. Rinc'on-Mora, "Accurate, compact and power-efficient li-ion battery charger circuit," IEEE Trans. Circuits Syst. II, Exp. Briefs, vol. 53, pp. 1180-1184, November 2006.

[8] S. Dearborn, "Charging li-ion batteries for maximum run times," Power Electron. Technol. Mag. vol. 31, pp. 40-49, April 2005.

[9] F. Musavi, M. Craciun, D.S. Gautam, W. Eberle, W.A. Dunford, "An LLC resonant DC-DC converter for wide output voltage range battery charging applications," IEEE Trans. on Power Electronics, vol. 28, pp. 5437-5445, March 2013.

[10] J. Deng, S. Li, S. Hu, C.C Mi, R. Ma, "Design methodology of LLC resonant converters for electric vehicle battery chargers," IEEE Trans. On Vehicular Technology, vol. 63, pp. 1581-1592, May 2014

[11] Z. Fang, T. Cai, S. Duan, C. Chen, "Optimal design methodology for LLC resonant converter in battery charging applications based on time-weighted average efficiency," IEEE Trans. On Power Electronics, vol. 30, pp.5469-5483, May 2015.

[12] L. R. Steigerwald, "A comparison of half bridge resonant converter topologies," IEEE Trans. on Power Electronics, vol.3, pp. 174-182, April 1988.

[13] C. Zhao, X. Wu, P. Meng, Z. Qian, “Optimum design consideration and implementation of a novel synchronous rectified soft-switched phase-shift full-bridge converter for low-output-voltage high-output-current applications," IEEE Trans. Power Electron., vol. 24, pp. 388-397, February 2009.

[14] U. Badstuebner, J. Biela, J. W. Kolar, "Design of an 99\%efficient, 5kW, phase-shift PWM DC-DC converter for telecom applications," In Proc. Applied Power Electronics Conference and Exposition (APEC), Palm Springs, USA, 2125 February 2010.

[15] J. W. Kim, D. Y. Kim, C. E. Kim, C. E., G. W. Moon, "Simple switching control technique for improving light load efficiency in a phase-shifted full-bridge converter with a server power system," IEEE Trans. Power Electron., vol.29, pp. 1562-1566, April 2014.

[16] A. F. Bakan, N. Altintas, and I. Aksoy, "An improved PSFB PWM DC-DC converter for high-power and frequency applications," IEEE Trans. Power Electron., Vol. 28, No. 1, pp. 64-74, Jan. 2013.

[17] S. Cetin, "High Efficiency Design Considerations for the Self-Driven Synchronous Rectified Phase Shifted Full Bridge Converters of Server Power Systems, Journal of Power Electronics, Vol.15, pp.634-643, May 2015.

[18] D. Y. Kim, C. E. Kim, G. W. Moon, "Variable delay time method in the phase-shifted full-bridge converter for reduced power consumption under light load conditions," IEEE Trans. Power Electron., vol. 28, pp. 5120-5127, November 2013.

[19] Timothy J. Han, Jared Preston, Seok J. Jang, and David Ouwerkerk, "A High Density 3.3 kW Isolated On-Vehicle Battery Charger Using SiC SBDs and SiC DMOSFETs", 2014 IEEE Transportation Electrification Conference and Expo (ITEC), June 2014. 